\title{
EULAR-PReS points to consider for the use of imaging in the diagnosis and management of juvenile idiopathic arthritis in clinical practice
}

\author{
A N Colebatch-Bourn, ${ }^{1,2}$ C J Edwards, ${ }^{1,3}$ P Collado, ${ }^{4}$ M-A D'Agostino, ${ }^{5,6}$ R Hemke, $^{7}$ \\ S Jousse-Joulin, ${ }^{8} \mathrm{M}$ Maas, ${ }^{7}$ A Martini, ${ }^{9,10}$ E Naredo, ${ }^{11}$ M Østergaard, ${ }_{1}^{12,13}$ \\ M Rooney, ${ }^{14} \mathrm{~N}$ Tzaribachev, ${ }^{15} \mathrm{M}$ A van Rossum, ${ }^{16,17}$ J Vojinovic, ${ }^{18} \mathrm{P}$ G Conaghan, ${ }^{19}$ \\ C Malattia ${ }^{9,10}$
}

\begin{abstract}
Handling editor Tore K Kvien
- Additional material is published online only. To view please visit the journal online (http://dx.doi.org/10.1136/ annrheumdis-2015-207892)
\end{abstract}

For numbered affiliations see end of article.

\section{Correspondence to} Dr A N Colebatch-Bourn, Department of Rheumatology, Yeovil District Hospital, Higher Kingston, Yeovil BA21 4AT, UK: alexandra.bourn@ydh.nhs.uk

ANC-B and CJE are joint first authors.

PGC and CM are joint senior authors.

Received 6 May 2015 Revised 12 July 2015 Accepted 14 July 2015 Published Online First 5 August 2015

\section{CrossMark}

To cite: ColebatchBourn AN, Edwards CJ, Collado P, et al. Ann Rheum Dis 2015;74:1946-1957.

\section{ABSTRACT}

To develop evidence based points to consider the use of imaging in the diagnosis and management of juvenile idiopathic arthritis ( JIA) in clinical practice. The task force comprised a group of paediatric rheumatologists, rheumatologists experienced in imaging, radiologists, methodologists and patients from nine countries. Eleven questions on imaging in JIA were generated using a process of discussion and consensus. Research evidence was searched systematically for each question using MEDLINE, EMBASE and Cochrane CENTRAL. Imaging modalities included were conventional radiography, ultrasound, MRI, CT, scintigraphy and positron emission tomography. The experts used the evidence obtained from the relevant studies to develop a set of points to consider. The level of agreement with each point to consider was assessed using a numerical rating scale. A total of 13277 references were identified from the search process, from which 204 studies were included in the systematic review. Nine points to consider were produced, taking into account the heterogeneity of JIA, the lack of normative data and consequent difficulty identifying pathology. These encompassed the role of imaging in making a diagnosis of $\mathrm{JIA}$, detecting and monitoring inflammation and damage, predicting outcome and response to treatment, use of guided therapies, progression and remission. Level of agreement for each proposition varied according to the research evidence and expert opinion. Nine points to consider and a related research agenda for the role of imaging in the management of JIA were developed using published evidence and expert opinion.

\section{INTRODUCTION}

Juvenile idiopathic arthritis (JIA) is a heterogeneous group of conditions with onset under the age of 16 years with unknown aetiology and persistence of symptoms for over 6 weeks. ${ }^{1}$ Imaging plays an important role in diagnosis and monitoring of patients with JIA, but until recently there were few studies in this area.

A European League against Rheumatism (EULAR) -Pediatric Rheumatology European Society (PReS) task force was convened to produce evidence and consensus-based recommendations on the use of imaging in the diagnosis and management of JIA in clinical practice for use by secondary care professionals caring for children with JIA, to help define standards of care for appropriate imaging.

\section{METHODS}

An expert group of paediatric rheumatologists, rheumatologists with imaging expertise, radiologists, methodologists and a fellow (16 people, representing 9 countries) participated. The task force used a rigorous procedure as described in the updated EULAR standardised operating procedures. $^{2}{ }^{3}$ Full methodological details are given in the online supplementary material S1.

At an initial meeting, members developed questions relevant to key aspects of the use of imaging in JIA. Eleven research questions were agreed by consensus, encompassing the role of imaging in making a diagnosis, detecting inflammation and damage, predicting outcome and response to treatment, the use of guided treatment, monitoring disease progression, and remission (see online supplementary text research questions S2). A detailed systematic search of the published literature was performed on studies involving the use of imaging in children with JIA. Imaging modalities included were X-ray described as conventional radiography (CR), ultrasound (US), MRI, CT, scintigraphy and positron emission tomography. Included studies were evaluated for risk of bias and applicability using the Quality Assessment of Diagnostic Accuracy Studies (QUADAS)-2 tool. ${ }^{4}$ Following presentation of the literature review at a second meeting, experts produced points to consider (PTC) with final agreement by a process of discussion and consensus. The available evidence for each recommendation was scored according to the Oxford Centre for Evidence-Based Medicine level of evidence. 5 The experts anonymously scored their level of agreement for each proposition using a $0-10$ numerical rating scale $(0=$ do not agree at all, $10=$ fully agree). Scores reflected research evidence and clinical expertise. ${ }^{2}$ An agenda for future research was also agreed upon following presentation of the literature review.

Three patient representatives (one child and two young adults with a diagnosis of JIA) and two parents of children with JIA participated in the development of the PTC at a Patient and Public Involvement event; further details are given in the online supplementary material S1.

\section{RESULTS}

The database search (November 2013) resulted in 13277 records leaving 10925 articles after 
Table 1 Points to consider, level of evidence, grade of recommendation and level of agreement

\begin{tabular}{|c|c|c|c|c|}
\hline \multicolumn{2}{|c|}{ Point to consider } & \multirow{2}{*}{$\begin{array}{l}\text { Level of } \\
\text { evidence } \\
3 b\end{array}$} & \multirow{2}{*}{$\begin{array}{l}\text { Grade of } \\
\text { recommendation } \\
\text { C }\end{array}$} & \multirow{2}{*}{$\begin{array}{l}\text { Level of agreement, mean } \\
\text { NRS } 0-10 \text { (range) } \\
9.07(6-10)\end{array}$} \\
\hline 1 & $\begin{array}{l}\text { US and MRI are superior to clinical examination in the evaluation of joint inflammation; these } \\
\text { techniques should be considered for more accurate detection of inflammation, in diagnosis } \\
\text { and assessing extent of joint involvement. }\end{array}$ & & & \\
\hline 2 & $\begin{array}{l}\text { When there is clinical diagnostic doubt, CR, US or MRI can be used to improve the certainty } \\
\text { of a diagnosis of JIA above clinical features alone. }\end{array}$ & $3 b$ & C & $9.43(9-10)$ \\
\hline 3 & $\begin{array}{l}\text { If detection of structural abnormalities or damage is required, CR can be used. However MRI } \\
\text { or US may be used to detect damage at an earlier time point than CR. }\end{array}$ & $3 b$ & C & $8.71(5-10)$ \\
\hline 4 & $\begin{array}{l}\text { In JIA imaging may be of particular benefit over routine clinical evaluation when assessing } \\
\text { certain joints, particularly the use of MRI in detecting inflammation of the TMJ and axial } \\
\text { involvement. }\end{array}$ & $3 b$ & C & $9.64(8-10)$ \\
\hline 5 & $\begin{array}{l}\text { Imaging in JIA may be considered for use as a prognostic indicator. Damage on CR can be } \\
\text { used for the prediction of further joint damage. Persistent inflammation on US or MRI may be } \\
\text { predictive of subsequent joint damage. }\end{array}$ & 4 & C & $9.07(5-10)$ \\
\hline 6 & $\begin{array}{l}\text { In JIA, US and MRI can be useful in monitoring disease activity given their sensitivity over } \\
\text { clinical examination and good responsiveness. MRI should be considered for monitoring axial } \\
\text { disease and TMJ. }\end{array}$ & $3 b$ & C & $9.07(7-10)$ \\
\hline 7 & $\begin{array}{l}\text { The periodic evaluation of joint damage should be considered. The imaging modality used } \\
\text { may be joint dependent. }\end{array}$ & $3 b$ & C & $8.29(5-10)$ \\
\hline 8 & US can be used for accurate placement of intra-articular injections. & $3 b$ & C & $9.64(8-10)$ \\
\hline 9 & $\begin{array}{l}\text { US and MRI can detect inflammation when clinically inactive disease is present; this may have } \\
\text { implications for monitoring. }\end{array}$ & $3 b$ & C & $8.86(5-10)$ \\
\hline
\end{tabular}

The level of evidence and grade of recommendation are based on the Oxford Centre for Evidence-Based Medicine system. ${ }^{5}$

Level of evidence scale, 1a-5; grade of recommendation scale; A-D. NRS, numerical rating scale $(0-10 ; 0=$ do not agree at all, $10=$ fully agree).

$\mathrm{CR}$, conventional radiography; JIA, juvenile idiopathic arthritis; TMJ, temporomandibular joint; US, ultrasound.

deduplication. Four hundred and thirty-three articles were included for detailed review once exclusions were made based on title or abstract. All full text articles written in English were retrieved for review, of which 244 articles were excluded leaving 189 articles for inclusion. The hand search identified 15 additional articles, resulting in a total of 204 articles for inclusion (see flow chart in the online supplementary figure S4). Articles that were relevant to multiple research questions were included in the review as necessary. The number of articles included per question is shown in the online supplementary table S5.

The task force produced nine PTC which are presented with the level of evidence, grade of recommendation and level of agreement in table 1 . The task force felt that the supporting data was not sufficient to produce 'recommendations' so they were categorised as 'points to consider'. Scores for risk of bias and applicability of the included studies according to QUADAS-2, a full reference list for articles included in each recommendation, and feedback given at the Patient and Public Involvement meeting are given in the online supplementary text S6 S7 and S8.

\section{Overarching principles}

The task force produced general statements that should be considered when interpreting the PTC. These principles cover the imaging needs of inflammatory arthritis is children and assume that other important differentials such as infection have been ruled out.

- 'JIA' is an umbrella term for all forms of inflammatory arthritis that begins before the age of 16 years, persists for more than 6 weeks and is of unknown origin. This heterogeneous group of diseases is currently classified according to the International League of Associations for Rheumatology classification. ${ }^{6}$ There is a lack of information on imaging related to JIA categories at present.
- There is a paucity of data on the joint-specific imaging features present during growth and skeletal development in healthy children. Understanding normative data is essential for interpretation of imaging abnormalities. For example, some physiological features of recently ossified bones can be misinterpreted as cortical erosions, cartilage thickness may vary with skeletal maturation and vascularity of epiphyses will change with ageing.

- Joint inflammation at certain developmental time points may cause specific structural changes, further challenging imaging assessment.

- The appropriateness and feasibility of different imaging modalities differs with age, related to radiation exposure and requirement for sedation. Every effort should be made to avoid unnecessary radiation exposure. However, there is a long established experience with the use of CR to demonstrate damage.

- Patient experience with different imaging modalities is affected by their age and development. It is important to provide a 'child friendly' environment.

\section{Points to consider}

Making a diagnosis of JIA

PTC 1: US and MRI are superior to clinical examination in the evaluation of joint inflammation; these techniques should be considered for more accurate detection of inflammation, in diagnosis and assessing extent of joint involvement.

Sixty-five studies compared clinical examination with imaging in the detection of inflammation in various joints, 40 with US, 27 with MRI, 5 with CR and 1 with positron emission tomography (table 2). The data is represented according to detection rates; for example, how many times more (>one fold) or less (<one fold) does imaging detect inflammation over clinical examination; this has the potential to increase false positive results. In general, US and MRI were able to detect joint inflammation more frequently than clinical examination; for example 
Table 2 Point to consider 1: Summary of included studies comparing imaging with CE in the detection of joint inflammation

Ultrasound

US knees vs CE

$\begin{array}{ll} & \text { Detection rate, mean (range) } \\ & \text { US vs CE }\end{array}$

Synovitis/effusion (12 studies) $)^{13} 14343876-83 \quad 1.19$-fold (0.14-3.67-fold)

PD vascularity $(2 \text { studies })^{38} 82$

Agreement $\mathrm{k}=0.54$ CE missed a significant no. of

effusions
13 studies $^{13} 1433343876-83$

MRI

MRI knees vs CE
studies $^{13-15} 36$ 72 $84-87$

\section{US hip vs CE}

5 studies $^{13} 16788889$

Synovitis/effusion (5 studies) ${ }^{13} 16788889$

Synovitis/effusion vs LOM (1 study $)^{89}$

Synovitis/effusion vs pain (1 study) $)^{89}$

studies

studies) $)^{14} 8586$

Effusion vs pain $(1 \text { study })^{13}$

US hands/wrists vs CE
4 studies $^{38} 409394$

\section{4 studies $^{38} 409394$}

Synovitis/effusion (3

0.93 -fold $(0.47-1.33$-fold $)$

PD vascularity $(2 \text { studies })^{38} 40$

0.96 -fold

GS synovitis had weaker correlation with clinical disease

activity than PD

Flexor/extensor tenosynovitis Significant association with clinical disease activity

MRI hip vs CE
5 studies $^{13} 15$ 90-92

0.85-fold (0.13-1.39-fold)

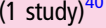

US ankles/feet vs CE

5 studies $^{38} 79$ 96-98

Synovitis/effusion (3 studies) $)^{38} 7996$

PD vascularity (1 study) $)^{38}$

0.97 -fold (0.86-1.04-fold)

0.57-fold

US TMJ vs CE3 studies 25100101

Synovitis/effusion (2 studies) ${ }^{25} 100$

11.7-fold (0.35-23.0-fold)

(Mn)

\section{Detection rate, mean}

(range)

MRI vs CE

Synovitis vs clinical swelling (3

1.02-fold (0.96-1.12-fold)

Effusion vs swelling (5 studies) ${ }^{13-15} 3685$

1.07 -fold $(0.75-1.33$-fold)

1.45 -fold (1.33-1.57-fold)

Synovial volume vs CRP (1 study $)^{87}$

$\mathrm{r}=0.51-0.80$

$\mathrm{p}=0.000-0.036$

Synovial hypertrophy vs pain (1 study) $)^{84}$

$\mathrm{r}=0.68-0.74$

MRI inflammation (4 studies) $)^{13} 159091 \quad 0.88$-fold (0.50-1.78-fold)

CR

CR knees vs CE
3 studies $^{13} 1585$

Joint distension vs pain (1 study $)^{13}$

1.57-fold

$\begin{array}{ll} & \text { (range) } \\ & \text { CR vs CE }\end{array}$

Joint distension vs swelling (3

studies) $)^{13} 1585$

CR vs CE

0.69 -fold (0.45-1.0-fold)

ynovial enhancement (1 study $)^{91} \quad 0.94$-fold

\section{MRI hands/wrists vs CE}

2 studies $^{19}{ }^{95}$

Synovitis volume vs total hand swelling

score (1 study)

Synovitis volume vs LOM (1 study) $)^{95}$

Synovitis score vs wrist swelling score $(1 \text { study })^{19}$

\section{CR hip vs CE}

1 study ${ }^{15}$

Joint distension vs clinical effusion (1 study) ${ }^{15}$

0.80 -fold

MRI TMJ vs CE

8 studies $^{25} 4142$ 102-106

Synovitis (6 studies) 254142 104-106

Synovitis vs reduced MIO (4 studies) $)^{25} 102103105$

$\mathrm{p}<0.05$

$r=0.76$

$\mathrm{p}<0.05$

MRI score significantly higher with higher

swelling score

$p<0.00001$

Acute changes (1 study) ${ }^{41}$

MRI ankles/feet vs CE

1 study $^{99}$

Tibiotalar synovitis (1 study) $)^{99}$

Subtalar synovitis (1 study) ${ }^{99}$

CR hands/wrists vs CE

1 study $^{93}$

Joint distension vs clinical effusion $\quad 0.63$-fold

$(1 \text { study })^{93}$ 
Table 2 Continued

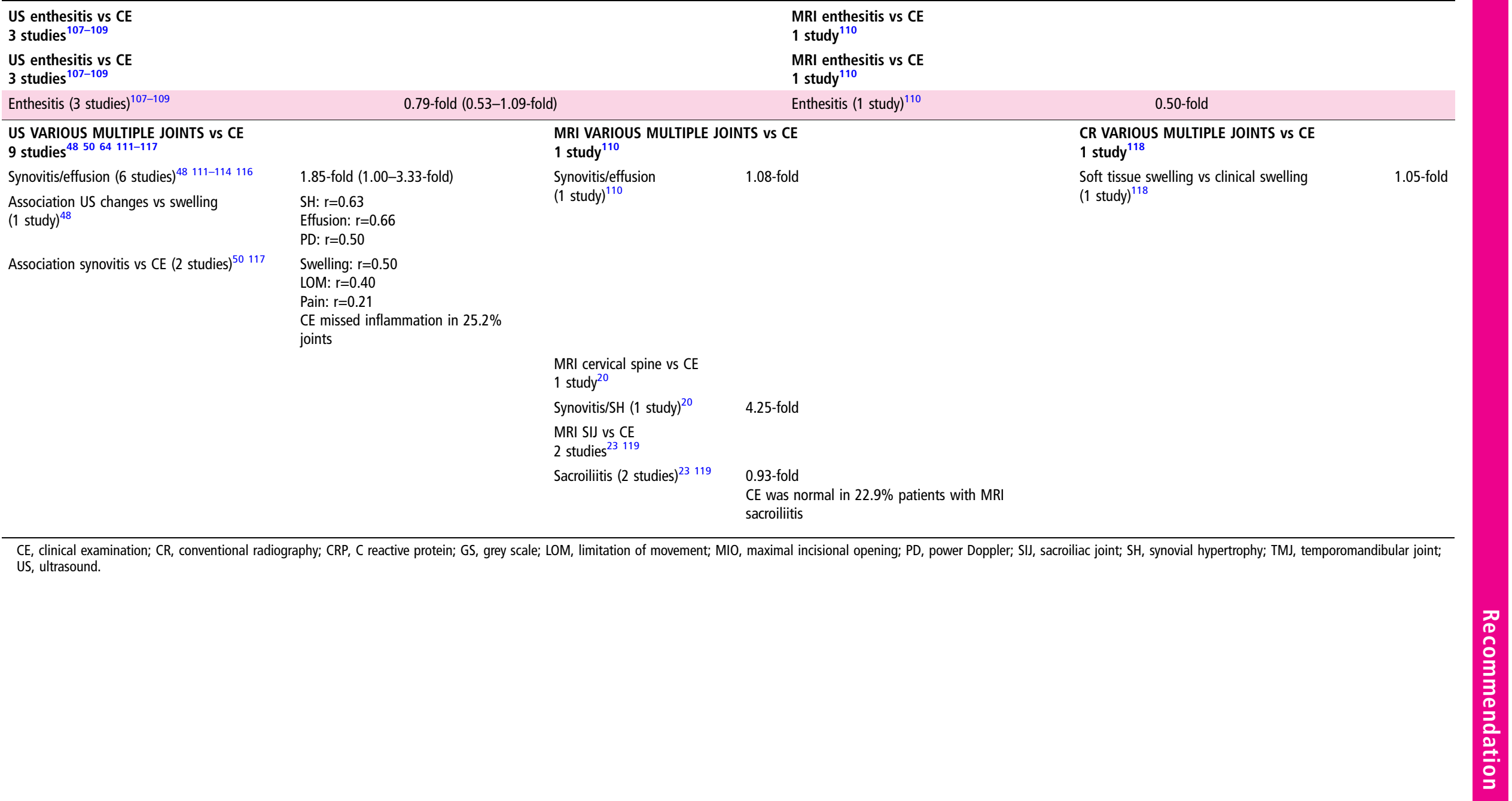

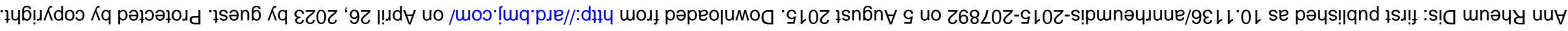


the mean (range) detection rate for synovitis and effusion at the knee was 1.19 -fold $(0.14-3.67$-fold) for US and 1.02-fold (0.96-1.12-fold) for MRI knee synovitis.

PTC 2: When there is clinical diagnostic doubt, CR, US or MRI can be used to improve the certainty of a diagnosis of JIA above clinical features alone.

The diagnosis of JIA is mainly based on clinical features and the exclusion of other causes of chronic arthritis. However this point illustrates the role of imaging when there is diagnostic doubt; no specific imaging signatures for JIA have been described yet, but imaging is helpful to narrow the differential diagnosis. Four studies compared imaging features in suspected/ proven JIA with either controls or other disease entities, including infectious arthritis, acute lymphoblastic leukaemia and haemophilia. ${ }^{7-10}$ US detected more joint inflammation than clinical examination; two studies specifically described US improving the diagnostic certainty in subjects with suspected JIA. ${ }^{11} 12$

\section{Detecting damage}

PTC 3: If detection of structural abnormalities or damage is required, CR can be used. However MRI or US may be used to detect damage at an earlier time point than CR.

Thirty-seven studies compared joint damage (erosions, joint space narrowing (JSN), deformity) detected by imaging with clinical findings suggestive of underlying damage, such as tenderness, limitation of movement and crepitus. In general, all imaging modalities appeared to detect less joint damage than suggested by clinical examination; for example the mean (range) detection rate for cartilage loss at the knee was 0.32 -fold for US, 0.63 -fold (0.20-1.0-fold) for MRI and 0.46-fold (0.230.71 -fold) for CR when compared with pain. ${ }^{13-15}$ This reflects the poor sensitivity of pain as an indicator of underlying damage.

When the imaging modalities are directly compared MRI and US detected more joint damage than CR, particularly at the hip (MRI vs CR detection rate, mean (range) 1.54-fold (1.082.0-fold); US vs CR detection rate, mean 2.29-fold), and at the wrist (MRI vs CR detection rate, 1.36-fold (1.0-2.0-fold)). ${ }^{13}$ 15-19

\section{Imaging specific joints}

PTC 4: In JIA imaging may be of particular benefit over routine clinical evaluation when assessing certain joints, particularly the use of MRI in detecting inflammation of the temporomandibular joint (TMJ) and axial involvement.

Cervical spine MRI appears better at detecting inflammation than clinical examination; one study showed $20 \%$ of patients had pain and/or limitation of movement whereas $85 \%$ had MRI inflammatory changes suggesting that cervical spine involvement in JIA is often clinically silent. ${ }^{20}$ MRI and CR have shown better detection rates than clinical examination for structural changes in the cervical spine (4.5-fold and mean, range 2.29 (1.58-3.0-fold)), respectively. ${ }^{21}{ }^{22}$ Abnormal sacroiliac joint (SIJ) imaging is also demonstrated despite a high rate of normal examination; for example, normal SIJ examination in $42.9 \%$ and $22.9 \%$, in patients with CR and MRI sacroiliitis, respectively. $^{23} 24$

Muller et $a l^{25}$ compared TMJ clinical examination and US with MRI changes, and found that examination correctly identified 58\% patients with active MRI TMJ arthritis compared with $33 \%$ for US, and missed inflammation in $42 \%$ and $67 \%$, respectively. They described reduced maximal incisal opening to be the best predictor of active MRI changes. ${ }^{26}$ Full data comparing the various imaging modalities with clinical examination of the TMJ is given in the online supplementary text $S 9$.

\section{Prognosis}

PTC 5: Imaging in JIA may be considered for use as a prognostic indicator. Damage on CR can be used for the prediction of further joint damage. Persistent inflammation on US or MRI may be predictive of subsequent joint damage.

Thirteen observational studies examined the relationship between baseline imaging and subsequent radiographic and clinical outcome; 11 with CR and 2 with MRI at baseline. The statement on US inflammation is therefore based on expert opinion; the findings are given in full in table 3 . In general, CR damage in the 1 st year has a moderate correlation with functional deterioration according to Steinbocker class, Childhood Health Assessment Questionnaire and physician/parent disability scores at 5 years, as well as with CR progression at 5 years. ${ }^{27-29}$ A baseline CR wrist adapted Sharp van der Heijde score $>1$ was shown to be predictive of CR progression at 5 years (OR, 8.2), and patients with erosions and/or JSN in the first 6 months of the study spent more time with clinically active disease and were less likely to achieve clinical remission on medication. ${ }^{30} 31$ Just one study described the correlation of baseline MRI wrist synovial volume with MRI erosive progression at 1 year; this found a moderate correlation, and all patients with high synovial volume at baseline had erosive progression. ${ }^{32}$

\section{Monitoring inflammation}

PTC 6: In JIA, US and MRI can be useful in monitoring disease activity given their sensitivity over clinical examination and good responsiveness. MRI should be considered for monitoring axial disease and TMJ.

Data comparing imaging with clinical examination in detecting joint inflammation is discussed in PTC 1 , and specific information on imaging the TMJ and for axial involvement is summarised in PTC 4. This section will consider the comparison of the ability of imaging to detect inflammation, responsiveness of imaging to change in inflammation, and which joints should be assessed.

\section{Comparison of the ability of imaging to detect inflammation}

Several studies compared US with MRI in the detection of inflammation, particularly at the knee. ${ }^{13} 14 \quad 33 \quad 34$ These studies have shown MRI to be better in detecting knee inflammation than US (mean detection rate 1.20-fold, range 0.63-1.56-fold) and in particular MRI was better than US in differentiating pannus from effusion. ${ }^{13}$ Knee MRI with contrast enhancement was more reliable at localising and differentiating synovial hypertrophy from synovial fluid particularly when there was $<5 \mathrm{~mm}$ of synovial hypertrophy, but the addition of contrast did not provide additional information in the assessment of inflammatory bone marrow lesions. ${ }^{35-37}$ Comparison of power Doppler with grey-scale wrist US has resulted in conflicting results, whereas the use of contrast significantly increased knee US synovial pixel intensity in those with symptomatic disease $(p=0.004)$ and asymptomatic disease $(p=0.0001)$, but not in those in clinical remission. ${ }^{38-40}$

Studies comparing TMJ US with MRI have shown a poor correlation between these modalities, with US missing $67-75 \%$ of TMJ MRI inflammation. ${ }^{25}{ }^{41}$ The use of MRI contrast enhancement improved the detection of MRI TMJ inflammation from $35.7 \%$ to $86.7 \% .^{42}$ One study examined the CR findings in patients with TMJ MRI synovitis and found significant correlation with abnormal condyle morphology and accentuated antegonial notching on $\mathrm{CR}$, and joints with both of these changes 


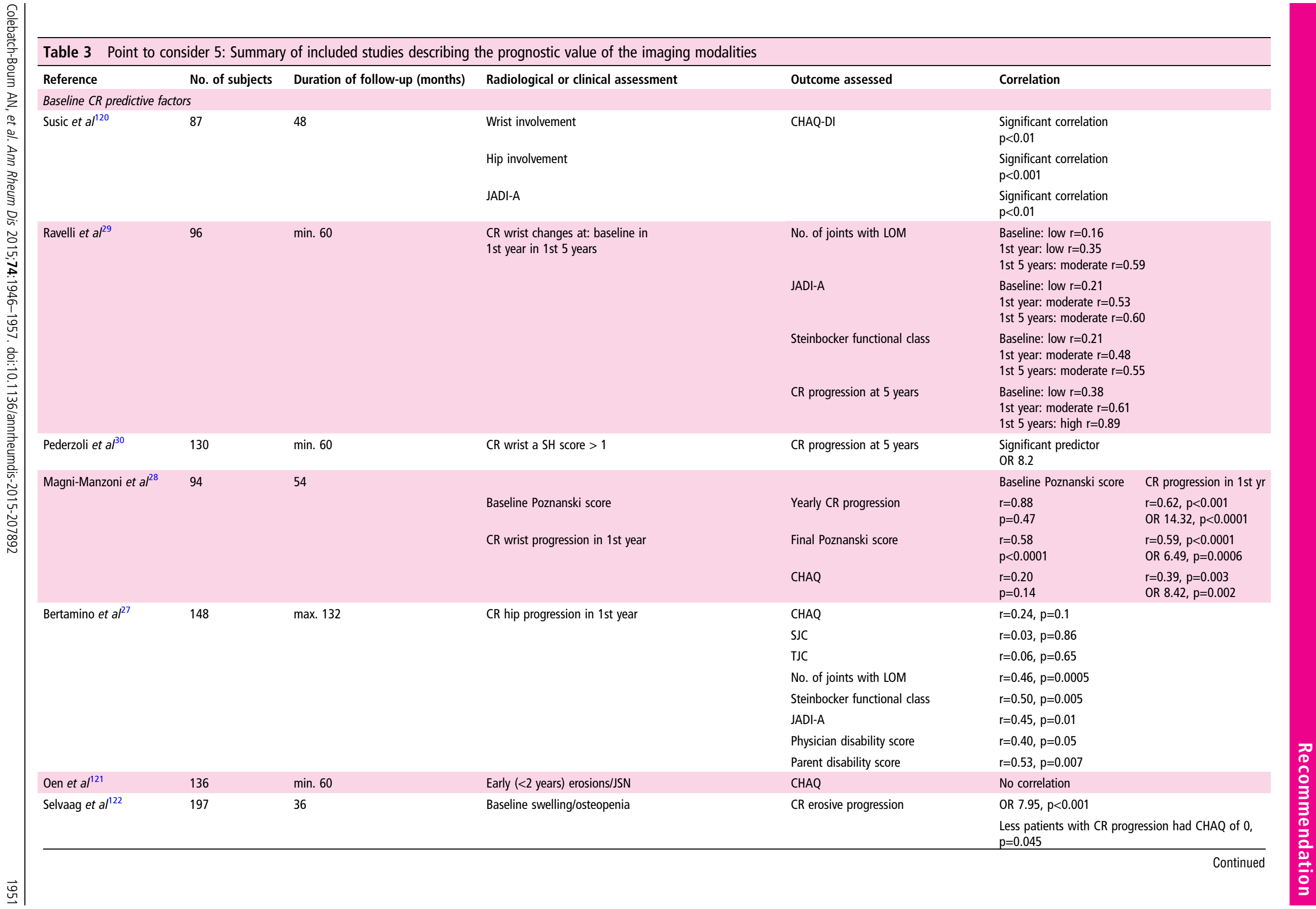


Table 3 Continued

\begin{tabular}{|c|c|c|c|c|c|}
\hline Reference & No. of subjects & Duration of follow-up (months) & Radiological or clinical assessment & Outcome assessed & Correlation \\
\hline \multirow[t]{2}{*}{ Ringold et $\left.a\right|^{31}$} & 104 & 29.9 & Early ( $<6$ months) erosions/JSN vs normal & $\begin{array}{l}\text { Time with active disease } \\
\text { CRM }\end{array}$ & $\begin{array}{l}\text { More time with active disease } \\
\mathrm{p}<0.001 \\
\text { Less chance of } C R M, R R=0.34, p<0.001\end{array}$ \\
\hline & & & $\mathrm{RF}+\mathrm{ve}$ vs $-\mathrm{ve}$ & & $\begin{array}{l}\text { More time with active disease } \\
p=0.07\end{array}$ \\
\hline \multirow[t]{2}{*}{ Oen et $a l^{54}$} & 88 & $\begin{array}{l}\text { Early ( }<2 \text { years) } \\
\text { Late }(1-20.8 \text { years })\end{array}$ & Late vs early JSN & CHAQ & $\begin{array}{l}\text { Significant correlation } \\
\text { Explains } 17.7 \% \text { of variation in CHAQ }\end{array}$ \\
\hline & & & Joint pain & & Explains $32.4 \%$ of variation in CHAQ \\
\hline Habib et $a /^{123}$ & 68 & - & ACPA & CR erosions & $\begin{array}{l}\text { Significant correlation } \\
p=0.004\end{array}$ \\
\hline Arvidsson et a/ $/^{124}$ & 103 & 324 & Baseline/early TMJ involvement & Micrognathia & $\begin{array}{l}66.7 \% \text { patients with micrognathia had baseline TMJ } \\
\text { involvement; } 33.3 \% \text { had CR TMJ involvement within } \\
2 \text { years }\end{array}$ \\
\hline \multicolumn{6}{|c|}{ Baseline MRI predictive factors } \\
\hline \multirow[t]{2}{*}{ Malattia et $a^{32}$} & 58 & 12 & Baseline wrist synovial volume & MRI erosive progression & $\begin{array}{l}\text { Correlation } r=0.42 \\
p<0.02 \\
\text { All patients with high synovial volume had erosive } \\
\text { progression }\end{array}$ \\
\hline & & & Baseline CRP & & $\begin{array}{l}\text { Correlation } r=0.40 \\
p<0.02\end{array}$ \\
\hline Gardner-Medwin et al ${ }^{125}$ & 10 & 12 & Baseline synovial hypertrophy in a clinically normal joint & Disease extension from monoarthritis & $\begin{array}{l}100 \% \text { patients developed clinical arthritis in other } \\
\text { joints }\end{array}$ \\
\hline
\end{tabular}

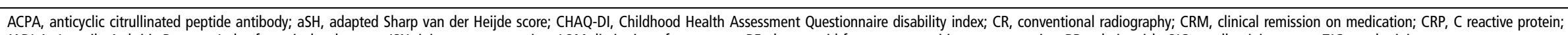
JADI-A, Juvenile Arthritis Damage Index for articular damage; JSN, joint space narrowing; LOM, limitation of movement; RF, rheumatoid factor; +ve, positive; -ve, negative; RR, relative risk; SJC, swollen joint count; TJC, tender joint count; TMJ, temporomandibular joint. 
on CR were 7.5 times more likely to have MRI synovitis (OR $7.55,95 \%$ CI 1.66 to $34.4, \mathrm{p}=0.009)$. $^{43}$

\section{Responsiveness of imaging to change in inflammation}

US and MRI have been shown to have good responsiveness to change in inflammation, as measured by standardised response means ( $\mathrm{SRM}, \geq 0.20$ small change, $\geq 0.50$ moderate, $\geq 0.80$ good). The mean (range) SRM for MRI wrist synovitis was good at 1.27 (0.51 to 1.69 ) and demonstrated ability to discriminate between different levels of clinical responder categories, whereas the SRM for MRI wrist bone marrow oedema was small at 0.22. ${ }^{19} 32{ }^{44}$ Similar levels of SRM have been described for MRI knee synovial hypertrophy $(0.68-0.70)$ and bone marrow oedema (0.15). ${ }^{45}$ A comparison of MRI wrist synovitis score with US showed higher MRI responsiveness (1.61) when compared with US grey-scale $(0.87)$ and US power Doppler (0.71). ${ }^{47}$

\section{Which joints to assess}

Studies describing the frequency of US joint inflammation in JIA have shown these changes to be most common in the knee $(\sim 30 \%)$ and wrist $(\sim 20 \%)$, then ankle, proximal interphalangeal joint and metatarsophalangeal joint ( 10\% each). ${ }^{48} \quad 49$ US power Doppler activity was most common in the wrist $(\sim 35 \%) .^{48} 49$ One study examined the frequency of US peripheral synovitis and found changes more commonly in the metatarsophalangeal joint (61.9\%) than in the metacarpophalangeal joint (39\%), with the first metatarsophalangeal joint and second metacarpophalangeal joint most frequently affected $(20 \%$ and $13 \%$, respectively). ${ }^{50}$

\section{Monitoring damage}

PTC 7: The periodic evaluation of joint damage should be considered. The imaging modality used may be joint dependent.

As for PTC 6, this section will consider the comparison of the ability of imaging to detect damage, responsiveness of imaging to change in damage, and which joints should be assessed. Data comparing imaging with clinical examination in detecting joint damage and comparing CR with MRI and US in detecting damage is discussed in part in PTC 3.

\section{Comparison of the ability of imaging to detect damage}

El-Miedany et $a l^{14}$ examined the role of MRI, US and CR in the detection of knee JSN and described a 3.14-fold detection rate of MRI compared with US, 4.40-fold for MRI compared with CR and 1.4-fold for US compared with CR. The addition of contrast to MRI enhanced the appreciation of depth of cartilage involvement by 1.42 -fold. Data describing the detection of wrist erosive changes have shown a detection rate for MRI compared with US of 1.92-fold, MRI compared with CR of 1.36-fold and US compared with CR of 1.0-fold. ${ }^{17-19} 40$

In terms of detecting damage of the TMJ, Muller et al ${ }^{25}$ showed that MRI condylar damage was detected in $25 \%$ of their cohort, whereas US detected only 17\% (1.47-fold). Weiss et $a l^{41}$ also described a poor correlation between these modalities, with only $50 \%$ agreement (detection rate 2.44 -fold).

\section{Responsiveness of imaging to change in damage}

Several studies examined the responsiveness of imaging to detect change in damage at the wrist, particularly with CR and MRI. The rate of change in CR score (Larsen, Sharp, Poznanski) appears to be greatest in the 1st year, which is mainly due to progression in JSN. ${ }^{28} 51$ This seems to slow after the 1 st year, whereas the rate of erosive change is steady from baseline to year 3; the rate of progression overall slows after 3rd third year. In general, the rate of JSN exceeds that of erosions and total score. ${ }^{29}$ When compared with CR, Malattia et al ${ }^{44}$ described the relative efficacy of MRI compared with CR erosion score to be $<1$ at year 1 ; that is, MRI was less responsive than CR in detecting erosive progression; the fact that cartilage assessment was not included in the MRI scoring systems might explain this result. A study of TMJ condylar changes showed that MRI identified significantly more changes than CR $(\mathrm{p} \leq 0.003)$, and MRI was superior to $\mathrm{CR}$ in following condylar changes over time: MRI condylar changes at baseline were found in 58.6\% compared with $80 \%$ at year 2 ; CR condylar changes were stable at baseline and year 2 at $30 \% .^{52}$

\section{Which joints to assess}

Studies describing the distribution of CR changes in 'early' (within 2 years of disease onset) and 'late' (up to 20.8 years of follow-up) disease have shown JSN to be most common in early disease in the wrist $(20 \%)$, hips (16\%), cervical spine $(5 \%)$, ankles (4\%) and knees (3\%) compared with 34\%, 25\%, 38\%, $15 \%$ and $6 \%$, respectively in late disease. ${ }^{53}{ }^{54}$ Rostom et al ${ }^{55}$ observed CR hip disease to start after 4 years of disease, whereas $80 \%$ had developed hip disease at 6 years, and $100 \%$ after 14 years. Other studies describing radiological features of JIA found most CR changes in the hands (57\%), knees (47\%), ankles (27\%) and feet (36\%), with erosions mainly in hands $(18 \%)$ and feet $(25 \%) .{ }^{56}$ The hands and feet were the area most likely to show CR damage progression at 6 months and 5 years. $^{57} 58$

\section{Guided treatment}

PTC 8: US can be used for accurate placement of intra-articular injections.

Studies summarising the role of imaging for guiding intra-articular steroid injections are given in online supplementary text S10, along with additional data on the use of imaging to assess and monitor efficacy of steroid injections. All studies used triamcinolone injections; doses and preparations varied according to the age of the patient and the joint being injected. Young et $\mathrm{al}^{59}$ used US to assess the accuracy of needle placement for steroid injections at various sites (joints and tendon sheaths), and described that US allowed accurate visualisation of the injection point in all 1444 injections. A study by Parra et $a l^{60}$ used CT to establish if US-guided TMJ injections had been accurately placed; needle placement was shown to be acceptable in 91\% (75\% required no needle adjustment, 16\% required minor adjustment) and unacceptable in $9 \%$ where the needle required major readjustment. A study of the efficacy of TMJ injections used MRI to assess needle placement accuracy according to the location (intra-articular or extra-articular) of the injected material on MRI acquired after injection; MRI confirmed that $65 \%$ of injections were accurately placed. ${ }^{61}$ A similar study using postinjection MRI of the SIJ described technical success in $100 \% .^{62}$

\section{Remission}

PTC 9: US and MRI can detect inflammation when clinically inactive disease is present; this may have implications for monitoring.

Several studies addressed the discrepancy between clinical remission and inflammation seen on US and MRI; these are summarised in the online supplementary text S11. Evidence of ongoing US synovitis has been described in 56.1-94.1\% of patients with clinically inactive joints, and $32 \%$ of patients with 
inactive disease showed US signs of synovial hypertrophy, effusion and power Doppler activity. ${ }^{63-65}$ In clinical remission, US grey-scale synovitis was seen in up to $84.1 \%$ of joints, and power Doppler activity in up to $48.6 \%$ of joints, with a nonsignificant trend to more US inflammation in clinical remission on medication compared with clinical remission off medication. ${ }^{39}{ }^{66-71}$ MRI knee inflammation has been demonstrated in up to $50 \%$ of patients in clinical remission and bone marrow oedema in $33.3 \%$ patients with clinically inactive joints. $^{72-74}$ Recent pilot studies have demonstrated that patients with subclinical US or MRI inflammation are more likely to develop active disease and disease progression, even within 6 months of follow-up. ${ }^{6470} 7475$

\section{Research agenda}

The group formulated a research agenda based on areas identified with a lack of currently available evidence, shown in box 1 .

\section{DISCUSSION}

These EULAR-PReS considerations for imaging provide important and novel advice for JIA in clinical practice. There is still significant research needed in this field, in particular consensus on understanding normative data to allow the interpretation of imaging abnormalities, agreement on appropriate MRI protocols and definitions of bone marrow oedema, synovitis and erosions, and suitability of the imaging modalities for detecting changes at specific joints. Our data is limited by the lack of specific information for each JIA disease subtype; this is reflected in the research agenda.

There are significant conceptual differences between imaging in adult and paediatric conditions, and consideration must be given to the appropriateness and feasibility of different imaging modalities which differs with age and developmental stage, as well as to economic issues such as the cost-effectiveness of the

\section{Box 1 Research agenda}

1. What are the age-specific changes in imaging, including age-specific intervals for imaging, development of an atlas of age-specific normal images and a registry as mechanism for pooling of data

2. Development of validated scoring systems including pathology definition (eg, differentiating reversible structural abnormalities from damage), imaging acquisition protocols and quantification

3. What are the imaging characteristics of the subtypes of JIA, and which target sites should be imaged?

4. What is the clinical significance of imaging-detected subclinical disease in diagnosis, monitoring and remission?

5. What is the usefulness of imaging-guided injection over non-imaging guided injection?

6. What is the prognostic value of specific imaging features, for example BM oedema?

7. Can imaging be used to assess and monitor disease progression and response to treatment including the development of structural damage?

8. What is the feasibility, cost and appropriate training for using US and MRI in JIA in clinical practice?

JIA, juvenile idiopathic arthritis; BM, bone marrow; US, ultrasound. intervention. Repeated unnecessary exposure to radiation from imaging should also be considered. We appreciate that access to individual imaging modalities may be insufficient to allow full implementation of these PTC; however most of the points include the use of US which is generally readily available. An economic evaluation was not included in the process as the primary aim was to discuss the clinical implications of imaging; overall the cost of implementing the PTC should be low.

After dissemination of the PTC by means of publication and presentation at European meetings, we would propose to perform a survey of awareness and their use, for example:

- Do you have access to musculoskeletal US and MRI routinely?

- Are you aware of and implementing the EULAR-PReS JIA imaging PTC?

- Have the PTC changed your clinical practice?

The task force agreed that it was not appropriate to create audit or implementation tools as the strength of data was only sufficient to develop PTC rather than recommendations.

In summary, we have developed nine PTC on the role of imaging in various clinical aspects in JIA. We would recommend that a similar rigorous process is followed to reassess the available data after an interval of 5 years.

\section{Author affiliations}

${ }^{1}$ NIHR Wellcome Trust Clinical Research Facility, University Hospital Southampton NHS Foundation Trust, Southampton, UK

${ }^{2}$ Department of Rheumatology, Yeovil District Hospital, Yeovil, UK

${ }^{3}$ MRC Lifecourse Epidemiology Unit, University of Southampton, Southampton General Hospital, Southampton, UK

${ }^{4}$ Hospital Universitario Severo Ochoa, Madrid, Spain

${ }^{5}$ Rheumatology Department, APHP, Hôpital Ambroise Paré, Boulogne-Billancourt, France

${ }^{6}$ Inserm U1173, Laboratoire d'Excellence INFLAMEX, Université Versailles

St. Quentin, Montigny-le-Bretonneux, France

${ }^{7}$ Academic Medical Centre Amsterdam, University of Amsterdam, Amsterdam, The Netherlands

${ }^{8}$ Brest University Medical School Hospital, Brest, France

${ }^{9}$ Institut Gaslini, Genova, Italy

${ }^{10}$ Department of Pediatrics, University of Genova, Genova, Italy

${ }^{11}$ Rheumatology Department, Hospital General Universitario Gregorio Maraňón, Madrid, Spain

${ }^{12}$ Copenhagen Center for Arthritis Research, Center of Rheumatology and Spine Diseases, Rigshospitalet, Glostrup, Denmark

${ }^{13}$ Department of Clinical Medicine, University of Copenhagen, Copenhagen, Denmark

${ }^{14}$ Queen's University Belfast, Belfast, UK

${ }^{15}$ Pediatric Rheumatology Research Institute, Bad Bramstedt, Germany

${ }^{16}$ Academic Medical Centre, Emma Children's Hospital, Amsterdam, The Netherlands

${ }^{17}$ Department of Rheumatology, Jan van Breemen Research Institute/Reade, Amsterdam, The Netherlands

${ }^{18}$ Faculty of Medicine University of Nis, Department of Pediatric Rheumatology, Clinic Center, Niš, Serbia

${ }^{19}$ NIHR Leeds Musculoskeletal Biomedical Research Unit, Leeds Institute of Rheumatic and Musculoskeletal Medicine, University of Leeds, Leeds, UK

Acknowledgements The authors thank Louise Falzon for her work in the development of the literature search strategy and Dr Brian Davidson for his involvement in the PPI event.

Contributors ANC-B and CJE performed the literature review and produced drafts of the manuscript with advice from PGC and CM. All authors were involved in the production of the recommendations, and have reviewed the final manuscript.

Funding EULAR.

Competing interests CJE: Speakers bureau and consultancy for Roche, BMS, Pfizer, Abbott, UCB, Samsung, MSD, GSK; M-AD'A: consulting fees and PI of international multicentre study on US for Bristol-Myers Squibb; speakers bureau for Roche, BMS, Pfizer, Abbott and UCB; research grant on US from PHRC; book royalties from Elsevier; PGC: speakers bureau or advisory boards for BMS, Pfizer and Roche.

Provenance and peer review Not commissioned; externally peer reviewed. 


\section{REFERENCES}

1 Prakken B, Albani S, Martini A. Juvenile idiopathic arthritis. Lancet 2011;377:2138-49.

2 van der Heijde D, Aletaha D, Carmona L, et al. 2014 Update of the EULAR standardised operating procedures for EULAR-endorsed recommendations. Ann Rheum Dis 2015;74:8-13.

3 Brouwers MC, Kho ME, Browman GP, et al. AGREE II: advancing guideline development, reporting and evaluation in health care. Can Med Assoc J 2010;182:E839-42.

4 Whiting PF, Rutjes AWS, Westwood ME, et al. QUADAS-2: a revised tool for the quality assessment of diagnostic accuracy studies. Ann Intern Med 2011;155:529-36.

5 Oxford Centre for Evidence Based Medicine-Levels of Evidence (updated March 2009). http://www.cebm.net/index.aspx?o=1025 (accessed 30 Oct 2014).

6 Petty RE, Southwood TR, Manners P, et al. International League of Associations for Rheumatology classification of juvenile idiopathic arthritis: second revision, Edmonton, 2001. J Rheumatol 2004:31:390-2.

7 Chlosta EM, Kuhns LR, Holt JF. The "patellar ratio" in hemophilia and juvenile rheumatoid arthritis. Radiology 1975;116:137-8.

8 Kirkhus $\mathrm{E}$, Flato $\mathrm{B}$, Riise $\mathrm{O}$, et al. Differences in MRI findings between subgroups of recent-onset childhood arthritis. Pediatr Radiol 2011;41:432-40.

9 Tafaghodi F, Aghighi Y, Rokni Yazdi H, et al. Predictive plain X-ray findings in distinguishing early stage acute lymphoblastic leukemia from juvenile idiopathic arthritis. Clin Rheumatol 2009:28:1253-8.

10 Uhl M, Krauss $\mathrm{M}$, Kern $\mathrm{S}$, et al. The knee joint in early juvenile idiopathic arthritis. An ROC study for evaluating the diagnostic accuracy of contrast-enhanced MR imaging. Acta Radiol 2001;42:6-9.

11 Filippou G, Cantarini L, Bertoldi I, et al. Ultrasonography vs. clinical examination in children with suspected arthritis. Does it make sense to use poliarticular ultrasonographic screening? Clin Exp Rheumatol 2011;29:345-50.

12 Ramos PC, Calvo C, Diaz-Delgado R. The role of musculoskeletal ultrasound in children with pain in the upper limbs [abstract]. Clin Exp Rheumatol 2011;29:410.

13 Eich GF, Halle F, Hodler J, et al. Juvenile chronic arthritis: imaging of the knees and hips before and after intraarticular steroid injection. Pediatr Radiol 1994;24:558-63.

14 El-Miedany YM, Housny IH, Mansour HM, et al. Ultrasound versus MRI in the evaluation of juvenile idiopathic arthritis of the knee. Joint Bone Spine 2001;68:222-30

15 Senac MO Jr, Deutsch D, Bernstein BH, et al. MR imaging in juvenile rheumatoid arthritis. AJR Am J Roentgenol 1988;150:873-8.

16 Fedrizzi MS, Ronchezel MV, Hilario MO, et al. Ultrasonography in the early diagnosis of hip joint involvement in juvenile rheumatoid arthritis. I Rheumatol 1997;24:1820-5.

17 Boavida P, Hargunani R, Owens CM, et al. Magnetic resonance imaging and radiographic assessment of carpal depressions in children with juvenile idiopathic arthritis: normal variants or erosions? I Rheumatol 2012;39:645-50.

18 Malattia C, Damasio MB, Magnaguagno F, et al. Magnetic resonance imaging, ultrasonography, and conventional radiography in the assessment of bone erosions in juvenile idiopathic arthritis. Arthritis Rheum 2008;59:1764-72.

19 Malattia C, Damasio MB, Pistorio A, et al. Development and preliminary validation of a paediatric-targeted MRI scoring system for the assessment of disease activity and damage in juvenile idiopathic arthritis. Ann Rheum Dis 2011;70:440-6.

20 Tzaribachev N, Tzaribachev C, Koos B. High prevalence of cervical spine and temporomandibular joint involvement in patients with juvenile idiopathic arthritis [abstract]. Arthritis Rheum 2012:64(Suppl 10):2026.

21 Oren B, Oren $\mathrm{H}$, Osma E, et al. Juvenile rheumatoid arthritis: cervical spine involvement and MRI in early diagnosis. Turk J Pediatr 1996;38:189-94.

22 Elhai M, Wipff J, Bazeli R, et al. Radiological cervical spine involvement in young adults with polyarticular juvenile idiopathic arthritis. Rheumatology (Oxford) 2013;52:267-75.

23 Lin C, Milojevic D. MRI Findings In Juvenile Spondyloarthopathy and effects of treatment on subsequent MRI [abstract]. Arthritis Rheum 2013;65(Suppl 10):288.

24 Burgos-Vargas R, Vazquez-Mellado J, Cassis N, et al. Genuine ankylosing spondylitis in children: a case-control study of patients with early definite disease according to adult onset criteria. J Rheumatol 1996;23:2140-7.

25 Muller L, Kellenberger CJ, Cannizzaro E, et al. Early diagnosis of temporomandibular joint involvement in juvenile idiopathic arthritis: a pilot study comparing clinical examination and ultrasound to magnetic resonance imaging. Rheumatology (Oxford) 2009;48:680-5.

26 Stabrun AE, Larheim TA, Hoyeraal HM. Temporomandibular joint involvement in juvenile rheumatoid arthritis. Clinical diagnostic criteria. Scand I Rheumatol 1989;18:197-204

27 Bertamino M, Rossi F, Pistorio A, et al. Development and initial validation of a radiographic scoring system for the hip in juvenile idiopathic arthritis. J Rheumatol 2010;37:432-9.

28 Magni-Manzoni S, Rossi F, Pistorio A, et al. Prognostic factors for radiographic progression, radiographic damage, and disability in juvenile idiopathic arthritis. Arthritis Rheum 2003:48:3509-17.
29 Ravelli A, loseliani M, Norambuena X, et al. Adapted versions of the Sharp/van der Heijde score are reliable and valid for assessment of radiographic progression in juvenile idiopathic arthritis. Arthritis Rheum 2007;56:3087-95.

30 Pederzoli S, Tsitsami E, Consolaro A, et al. Early functional impairment and structural changes predict long-term damage in children with polyarticular juvenile idiopathic arthritis [abstract]. Clin Exp Rheumatol 2011;29:456.

31 Ringold $S$, Seidel KD, Koepsell TD, et al. Inactive disease in polyarticular juvenile idiopathic arthritis: current patterns and associations. Rheumatology (Oxford) 2009;48:972-7.

32 Malattia C, Damasio MB, Basso C, et al. Novel automated system for magnetic resonance imaging quantification of the inflamed synovial membrane volume in patients with juvenile idiopathic arthritis. Arthritis Care Res 2012;64:1657-64.

33 Pascoli L, Napier NJ, Wray M, et al. A prospective comparative study of three methods of assessment of the knee joint in juvenile idiopathic arthritis: clinical examination, ultrasound and MRI (a newly developed knee MRI scoring system) [abstract]. Ann Rheum Dis 2012;71(Suppl 3):263.

34 Pascoli L, Napier NJ, Wray M, et al. Knee joint in JIA: a prospective evaluation of clinical examination, ultrasound and MRI assessment. A newly developed knee MRI scoring system in JIA [abstract]. Rheumatology (Oxford) 2010;49(Suppl 1): i86-7.

35 Hemke R, Kuijpers TW, van den Berg JM, et al. The diagnostic accuracy of unenhanced MRI in the assessment of joint abnormalities in juvenile idiopathic arthritis. Eur Radiol 2013;23:1998-2004.

36 Herve-Somma CM, Sebag GH, Prieur AM, et al. Juvenile rheumatoid arthritis of the knee: MR evaluation with Gd-DOTA. Radiology 1992;182:93-8.

37 Johnson $\mathrm{K}$, Wittkop B, Haigh F, et al. The early magnetic resonance imaging features of the knee in juvenile idiopathic arthritis. Clin Radiol 2002;57:466-71.

38 Collado P, Naredo E, Calvo C, et al. Reduced joint assessment vs comprehensive assessment for ultrasound detection of synovitis in juvenile idiopathic arthritis. Rheumatology (Oxford) 2013;52:1477-84.

39 Doria AS, Kiss MH, Lotito AP, et al. Juvenile rheumatoid arthritis of the knee: evaluation with contrast-enhanced color Doppler ultrasound. Pediatr Radiol 2001:31:524-31.

40 Malattia C, Damasio MB, Pistorio A, et al. Development and preliminary validation of a wrist ultrasound scoring system for the assessment of disease activity and damage in JIA: A comparison with MRI and clinical examination [abstract]. Clin Exp Rheumatol 2011:29:385.

41 Weiss PF, Arabshahi B, Johnson A, et al. High prevalence of temporomandibular joint arthritis at disease onset in children with juvenile idiopathic arthritis, as detected by magnetic resonance imaging but not by ultrasound. Arthritis Rheum 2008:58:1189-96.

42 Kuseler A, Pedersen TK, Herlin T, et al. Contrast enhanced magnetic resonance imaging as a method to diagnose early inflammatory changes in the temporomandibular joint in children with juvenile chronic arthritis. J Rheumatol 1998;25:1406-12.

43 Abramowicz S, Simon L, Susarla HK, et al. Are panoramic radiographs predictive of temporomandibular joint synovitis in children with juvenile idiopathic arthritis? [abstract]. J Oral Maxillofac Surg 2013;71(Suppl 1):e93.

44 Malattia C, Consolaro A, Pederzoli S, et al. MRI versus conventional measures of disease activity and structural damage in evaluating treatment efficacy in juvenile idiopathic arthritis. Ann Rheum Dis 2013;72:363-8.

45 Hemke $R$, van Rossum MA, van Veenendaal $M$, et al. Reliability and responsiveness of the Juvenile Arthritis MRI Scoring (JAMRIS) system for the knee. Eur Radiol 2013;23:1075-83.

46 Hemke R, van Veenendaal $M$, van den Berg JM, et al. One-year followup study on clinical findings and changes in magnetic resonance imaging-based disease activity scores in juvenile idiopathic arthritis. J Rheumatol 2014;41:119-27.

47 Malattia C, Consolaro A, Pederzoli S, et al. MRI and ultrasound versus conventional measures of disease activity and structural damage in evaluating treatment efficacy in JIA. Do these imaging techniques have an additional value? [abstract]. Pediatr Rheumatol 2011;9(Suppl 1):012.

48 Magni-Manzoni S, Epis O, Ravelli A, et al. Comparison of clinical versus ultrasound-determined synovitis in juvenile idiopathic arthritis. Arthritis Rheum 2009;61:1497-504.

49 Magni-Manzoni S, Scire CA, Ravelli A, et al. Ultrasound-detected synovial abnormalities are frequent in clinically inactive juvenile idiopathic arthritis, but do not predict a flare of synovitis. Ann Rheum Dis 2013;72:223-8.

50 Breton S, Jousse-Joulin S, Cangemi $C$, et al. Comparison of clinical and ultrasonographic evaluations for peripheral synovitis in juvenile idiopathic arthritis. Semin Arthritis Rheum 2011;41:272-8.

51 Rossi F, Di Dia F, Galipo 0, et al. Use of the Sharp and Larsen scoring methods in the assessment of radiographic progression in juvenile idiopathic arthritis. Arthritis Rheum 2006;55:717-23.

52 Pedersen TK, Kuseler A, Gelineck J, et al. A prospective study of magnetic resonance and radiographic imaging in relation to symptoms and clinical findings of the temporomandibular joint in children with juvenile idiopathic arthritis. J Rheumatol 2008;35:1668-75. 
53 Lang BA, Schneider R, Reilly BJ, et al. Radiologic features of systemic onset juvenile rheumatoid arthritis. J Rheumatol 1995;22:168-73.

54 Oen K, Reed M, Malleson PN, et al. Radiologic outcome and its relationship to functional disability in juvenile rheumatoid arthritis. J Rheumatol 2003;30:832-40.

55 Rostom S, Amine B, Bensabbah R, et al. Hip involvement in juvenile idiopathic arthritis. Clin Rheumatol 2008;27:791-4.

56 van Rossum MA, Zwinderman AH, Boers $\mathrm{M}$, et al. Radiologic features in juvenile idiopathic arthritis: a first step in the development of a standardized assessment method. Arthritis Rheum 2003;48:507-15.

57 van Rossum MA, Boers M, Zwinderman AH, et al. Development of a standardized method of assessment of radiographs and radiographic change in juvenile idiopathic arthritis: introduction of the Dijkstra composite score. Arthritis Rheum 2005; $52: 2865-72$.

58 Williams RA, Ansell BM. Radiological findings in seropositive juvenile chronic arthritis (juvenile rheumatoid arthritis) with particular reference to progression. Ann Rheum Dis 1985;44:685-93.

59 Young CM, Shiels WE 2nd, Coley BD, et al. Ultrasound-guided corticosteroid injection therapy for juvenile idiopathic arthritis: 12-year care experience. Pediatr Radiol 2012:42:1481-9.

60 Parra DA, Chan M, Krishnamurthy G, et al. Use and accuracy of US guidance for image-guided injections of the temporomandibular joints in children with arthritis. Pediatr Radiol 2010;40:1498-504.

61 Saurenmann RK, Muller L, Schroeder S, et al. Efficacy of intra-articular steroid injection into the temporomandibular joint in children with juvenile idiopathic arthritis [abstract]. Arthritis Rheum 2009;60(Suppl 10):243.

62 Fritz J, Tzaribachev N, Thomas C, et al. Evaluation of MR imaging guided steroid injection of the sacroiliac joints for the treatment of children with refractory enthesitis-related arthritis. Eur Radiol 2011;21:1050-7.

63 Donati C, Soldi A, De Lucia O, et al. Comparison of clinical and ultrasonographic examination of 7200 joints in $100 \mathrm{JIA}$ patients satisfying Wallace criteria of inactive disease (ID), suggests to add ultrasonography as a new criteria of ID [abstract]. Ann Rheum Dis 2012;71(Suppl 3):426.

64 Nielsen HE, Strandberg C, Andersen S, et al. Ultrasonographic examination in juvenile idiopathic arthritis is better than clinical examination for identification of intraarticular disease. Dan Med J 2013;60:A4669.

65 Halbwachs M, Durand G. Should joint ultrasound contribute to therapeutic decisions in juvenile idiopathic arthritis? [abstract]. Arthritis Rheum 2012;64(Suppl 10):2023.

66 Collado P, Gamir ML, Merino R, et al. Detection of synovitis in clinically inactive juvenile idiopathic arthritis patients by ultrasonography with power Doppler [abstract]. Arthritis Rheum 2012;64(Suppl 10):123.

67 Molina C, Santos C, Modesto C, et al. Subclinical synovitis detected by ultrasound in patients with oligoarticular JIA in clinical remission [abstract]. Clin Exp Rheumatol 2011;29:416.

68 Parsa MF, Rullo OJ, Woo JMP, et al. Ultrasound and plasma osteopontin improve the assessment of remission in oligoarticular juvenile idiopathic arthritis [abstract]. Arthritis Rheum 2011;63(Suppl 10):254.

69 Rebollo-Polo M, Koujok K, Weisser C, et al. Ultrasound findings on patients with juvenile idiopathic arthritis in clinical remission. Arthritis Care Res 2011;63:1013-19.

70 Silva V, Mitraud S, Furtado R, et al. Preliminary prospective study of ultrasonography in patients with juvenile idiopathic arthritis in clinical remission: subclinical synovitis may predict flare? [abstract]. Arthritis Rheum 2013;65(Suppl 10):298.

71 Bugni Miotto e Silva V, de Freitas Tavares da Silva C, de Aguiar Vilela Mitraud S, et al. Do patients with juvenile idiopathic arthritis in remission exhibit active synovitis on joint ultrasound? Rheumatol Int 2014;34:937-45.

72 Hemke R, Maas M, Veenendaal M, et al. Contrast-enhanced MRI compared with the physical examination in the evaluation of disease activity in juvenile idiopathic arthritis. Eur Radiol 2014;24:327-34.

73 Van Veenendaal M, Hemke R, Bos MI, et al. MRI evaluation of clinical remission in juvenile idiopathic arthritis [abstract]. Pediatr Rheumatol Online J 2011;9(Suppl 1):P114.

74 Van Veenendaal M, Hemke R, Bos Ml, et al. Magnetic resonance imaging in follow-up of clinical remission in juvenile idiopathic arthritis [abstract]. Arthritis Rheum 2012;64(Suppl 10):1021.

75 Tzaribachev N, Horger M, Fritz J. Silent arthritis progression in children with juvenile idiopathic arthritis detected by magnetic resonance imaging [abstract]. Arthritis Rheum 2011;63(Suppl 10):866.

76 Algergawy S, Haliem T, Al-Shaer O. Clinical, laboratory, and ultrasound assessment of the knee in juvenile rheumatoid arthritis. Clin Med Insights Arthritis Musculoskelet Disord 2011:4:21-7.

77 Cellerini M, Salti S, Trapani S, et al. Correlation between clinical and ultrasound assessment of the knee in children with mono-articular or pauci-articular juvenile rheumatoid arthritis. Pediatr Radiol 1999;29:117-23.

78 Frosch M, Foell D, Ganser G, et al. Arthrosonography of hip and knee joints in the follow up of juvenile rheumatoid arthritis. Ann Rheum Dis 2003;62:242-4.
79 Janow GL, Panghaal V, Trinh A, et al. Detection of active disease in juvenile idiopathic arthritis: sensitivity and specificity of the physical examination vs ultrasound. J Rheumatol 2011;38:2671-4.

80 Kakati P, Sodhi KS, Sandhu MS, et al. Clinical and ultrasound assessment of the knee in children with juvenile rheumatoid arthritis. Indian J Pediatr 2007:74:831-6.

81 Shahin AA, el-Mofty SA, el-Sheikh EA, et al. Power Doppler sonography in the evaluation and follow-up of knee involvement in patients with juvenile idiopathic arthritis. Z Rheumatol 2001;60:148-55.

82 Shanmugavel C, Sodhi KS, Sandhu MS, et al. Role of power Doppler sonography in evaluation of therapeutic response of the knee in juvenile rheumatoid arthritis. Rheumatol Int 2008;28:573-8.

83 Sureda D, Quiroga $S$, Arnal $C$, et al. Juvenile rheumatoid arthritis of the knee: evaluation with US. Radiology 1994;190:403-6.

84 Cakmakci H, Kovanlikaya A, Unsal E. Short-term follow-up of the juvenile rheumatoid knee with fat-saturated 3D MRI. Pediatr Radiol 2001;31:189-95.

85 Gylys-Morin VM, Graham TB, Blebea JS, et al. Knee in early juvenile rheumatoid arthritis: MR imaging findings. Radiology 2001;220:696-706.

86 Thapa M, Spalding SJ, Hashkes PJ, et al. MRI findings from the trial of early aggressive therapy (TREAT) study [abstract]. Pediatr Rheumatol Online J 2012;10 (Suppl 1):A36.

87 Workie DW, Graham TB, Laor T, et al. Quantitative MR characterization of disease activity in the knee in children with juvenile idiopathic arthritis: a longitudinal pilot study. Pediatr Radiol 2007;37:535-43.

88 Friedman S, Gruber MA. Ultrasonography of the hip in the evaluation of children with seronegative juvenile rheumatoid arthritis. J Rheumatol 2002;29:629-32.

89 Silva V, Faquin G, Nicácio A, et al. Association between the ultrasonographic and clinical findings in the hips of patients with juvenile idiopathic arthritis. Rev Bras Reumatol 2013;53:322-7.

90 Argyropoulou MI, Fanis SL, Xenakis T, et al. The role of MRI in the evaluation of hip joint disease in clinical subtypes of juvenile idiopathic arthritis. Br J Radiol 2002:75:229-33.

91 El-Azeem MIA, Taha HA, El-Sherif AM. Role of MRI in evaluation of hip joint involvement in juvenile idiopathic arthritis. Egypt Rheumatol 2012;34:75-82.

92 Nistala K, Babar J, Johnson K, et al. Clinical assessment and core outcome variables are poor predictors of hip arthritis diagnosed by MRI in juvenile idiopathic arthritis. Rheumatology (Oxford) 2007:46:699-702.

93 Karmazyn B, Bowyer SL, Schmidt KM, et al. US findings of metacarpophalangeal joints in children with idiopathic juvenile arthritis. Pediatr Radiol 2007;37:475-82.

94 Laurell L, Court-Payen M, Nielsen S, et al. Ultrasonography and color Doppler in juvenile idiopathic arthritis: diagnosis and follow-up of ultrasound-guided steroid injection in the wrist region. A descriptive interventional study. Pediatr Rheumatol Online J 2012;10:11.

95 Graham TB, Laor T, Dardzinski BJ. Quantitative magnetic resonance imaging of the hands and wrists of children with juvenile rheumatoid arthritis. J Rheumatol 2005:32:1811-20.

96 Pascoli L, Wright S, McAllister C, et al. Prospective evaluation of clinical and ultrasound findings in ankle disease in juvenile idiopathic arthritis: importance of ankle ultrasound. J Rheumatol 2010;37:2409-14.

97 Hendry GJ, Gardner-Medwin J, Steultjens MP, et al. Frequent discordance between clinical and musculoskeletal ultrasound examinations of foot disease in juvenile idiopathic arthritis. Arthritis Care Res 2012;64:441-7.

98 Laurell L, Court-Payen M, Nielsen S, et al. Ultrasonography and color Doppler in juvenile idiopathic arthritis: diagnosis and follow-up of ultrasound-guided steroid injection in the ankle region. A descriptive interventional study. Pediatr Rheumatol Online J 2011;9:4.

99 Remedios D, Martin K, Kaplan G, et al. Juvenile chronic arthritis: diagnosis and management of tibio-talar and sub-talar disease. Br J Rheumatol 1997:36:1214-17.

100 Melchiorre D, Falcini F, Kaloudi O, et al. Sonographic evaluation of the temporomandibular joints in juvenile idiopathic arthritis. J Ultrasound 2010;13:34-7.

101 Pieroni G, Lanza C, Fabrizzi G, et al. Use of ultrasonography for the diagnosis of temporomandibular joint disorders in children with juvenile idiopathic arthritis [abstract]. Pediatr Radiol 2010;40:1157.

102 Abdul-Aziez OA, Saber NZ, El-Bakry SA, et al. Serum S100A12 and temporomandibular joint magnetic resonance imaging in juvenile idiopathic arthritis Egyptian patients: a case control study. Pak J Biol Sci 2010;13: $101-13$.

103 Abramowicz S, Susarla HK, Kim S, et al. Physical findings associated with active temporomandibular joint inflammation in children with juvenile idiopathic arthritis. J Oral Maxillofac Surg 2013;71:1683-7.

104 Kuseler A, Pedersen TK, Gelineck J, et al. A 2 year followup study of enhanced magnetic resonance imaging and clinical examination of the temporomandibular joint in children with juvenile idiopathic arthritis. J Rheumatol 2005;32:162-9.

105 Mohammed Y, Saeed O, Zaghloul N, et al. Juvenile idiopathic arthritis and the temporomandibular joint. Alexandria J Med 2012;48:123-9. 
106 Zwir L, Terreri MT, Sousa S, et al. Does intense synovial enhancement in temporomandibular joints of juvenile idiopathic arthritis patients correlate with disease activity? [abstract]. Ann Rheum Dis 2012;71(Suppl 3):264.

107 Jousse-Joulin S, Breton S, Cangemi C, et al. Ultrasonography for detecting enthesitis in juvenile idiopathic arthritis. Arthritis Care Res 2011;63:849-55.

108 Laurell L, Court-Payen M, Nielsen S, et al. Ultrasonography and color Doppler of proximal gluteal enthesitis in juvenile idiopathic arthritis: a descriptive study. Pediatr Rheumatol Online J 2011:9:22.

109 Toib D, French AR, Dahiya N, et al. The role of ultrasound in B mode and power Doppler sonography in the diagnosis of enthesitis in children [abstract]. Arthritis Rheum 2010;62(Suppl 10):1633.

110 Rachlis AC, Babyn PS, Lobo-Mueller E, et al. Whole body magnetic resonance imaging in juvenile spondyloarthritis: will it provide vital information compared to clinical exam alone? [abstract]. Arthritis Rheum 2011;63(Suppl 10):749.

111 Collado P, Merino R, Grana J Sr, et al. Grey-scale ultrasonography with power Doppler technique: An available tool for the assessment of subclinical joint inflammatory activity in juvenile idiopathic arthritis [abstract]. Arthritis Rheum 2012;64(Suppl 10):122.

112 Haslam KE, McCann LJ, Wyatt $S$, et al. The detection of subclinical synovitis by ultrasound in oligoarticular juvenile idiopathic arthritis: a pilot study. Rheumatology (Oxford) 2010;49:123-7.

113 Jousse-Joulin S, Breton S, Cangemi C, et al. Ultrasound abnormalities of peripheral joints in juvenile idiopathic arthritis and correlation with clinical examination [abstract]. Arthritis Rheum 2009;60(Suppl 10):1903.

114 Sparchez M, Fodor D, Miu N. The role of Power Doppler ultrasonography in comparison with biological markers in the evaluation of disease activity in Juvenile Idiopathic Arthritis. Med Ultrason 2010;12:97-103.

115 Ranjan S, Jahan A, Yadav T, et al. Evaluation of synovial inflammation in juvenile idiopathic arthritis by power color doppler and spectral doppler ultrasonography. Indian J Pediatr 2014;81:29-35.
116 Wabi MO, Amine B, Aktaou S, et al. Ultrasonography signs in metacarpophalangeal and metatarsophalangeal joints in children suffering from juvenile idiopathic arthritis in Morocco: comparison of clinical evaluation [abstract]. Ann Rheum Dis 2013;72(Suppl 3):999.

117 Varshney AN, Singh NK, Shukla RC, et al. Detection of active disease by musculoskeletal ultrasonography in patients of juvenile idiopathic arthritis [abstract]. Indian J Rheumatol 2013;8(Suppl):1.

118 Tateishi U, Imagawa T, Kanezawa N, et al. PET assessment of disease activity in children with juvenile idiopathic arthritis. Pediatr Radiol 2010;40:1781-8.

119 Bollow M, Biedermann T, Kannenberg J, et al. Use of dynamic magnetic resonance imaging to detect sacroilitits in HLA-B27 positive and negative children with juvenile arthritides. J Rheumatol 1998;25:556-64.

120 Susic GZ, Stojanovic RM, Pejnovic NN, et al. Analysis of disease activity, functional disability and articular damage in patients with juvenile idiopathic arthritis: a prospective outcome study. Clin Exp Rheumatol 2011;29:337-44.

121 Oen K, Malleson PN, Cabral DA, et al. Early predictors of longterm outcome in patients with juvenile rheumatoid arthritis: subset-specific correlations. J Rheumatol 2003;30:585-93.

122 Selvaag AM, Flato B, Dale K, et al. Radiographic and clinical outcome in early juvenile rheumatoid arthritis and juvenile spondyloarthropathy: a 3-year prospective study. J Rheumatol 2006;33:1382-91.

123 Habib HM, Mosaad YM, Youssef HM. Anti-cyclic citrullinated peptide antibodies in patients with juvenile idiopathic arthritis. Immunol Invest 2008;37:849-57.

124 Arvidsson LZ, Fjeld MG, Smith HJ, et al. Craniofacial growth disturbance is related to temporomandibular joint abnormality in patients with juvenile idiopathic arthritis, but normal facial profile was also found at the 27-year follow-up. Scand $J$ Rheumatol 2010;39:373-9.

125 Gardner-Medwin JM, Killeen OG, Ryder CA, et al. Magnetic resonance imaging identifies features in clinically unaffected knees predicting extension of arthritis in children with monoarthritis. J Rheumatol 2006;33:2337-43. 